\title{
Crescimento de Camada Intermetálica na Soldagem por Fricção Rotativa de Alumínio e Aço, Assistida com Preaquecimento por Indução Eletromagnética
}

\author{
Marlon Antônio Pinheiro ${ }^{1,2}$ (D) , Alexandre Queiroz Bracarense ${ }^{3}$ (D) \\ ${ }^{1}$ Universidade Federal de Minas Gerais - UFMG, Departamento de Engenharia Mecânica, Laboratório de Robótica Simulação e Soldagem, Belo Horizonte, MG, \\ Brasil. \\ ${ }^{2}$ Centro Federal de Educação Tecnológica de Minas Gerai - CEFET-MG, Divinópolis, MG, Brasil. \\ ${ }^{3}$ Universidade Federal de Minas Gerais - UFMG, Departamento de Engenharia Mecânica, Laboratório de Robótica Simulação e Soldagem, Belo Horizonte, MG, \\ Brasil.
}

Como citar: Pinheiro MA, Bracarense AQ. Crescimento de camada intermetálica na soldagem por fricção rotativa de alumínio e aço, assistida com preaquecimento por indução eletromagnética. Soldagem \& Inspeção. 2021;26:e2542. https://doi.org/10.1590/0104$9224 / \mathrm{S} 125.42$

\begin{abstract}
Resumo: A soldagem de juntas dissimilares de alumínio e aço pode ser obtida pelo processo de friç̧ão, que é um processo de soldagem no estado sólido. Esse processo ocorre à temperaturas abaixo do ponto de fusão dos metais e tem como principal mecanismo de união, a difusão. Apresenta-se como opção interessante de processo de soldagem. Por gerar menor tensão residual, menor distorção e baixa formação de trincas. Entretanto um dos grandes desafios de união de materiais dissimilares é a formação de compostos intermetálicos, que pode reduzir a resistência mecânica das juntas. Este trabalho apresenta a soldagem de topo por fricção rotativa de Alumínio ASTM A6351 T6 e Aço SAE 1020 e tem como objetivo avaliar o crescimento de camada intermetálica, com e sem a utilização de preaquecimento do aço Além disso, este trabalho também busca avaliar estruturas obtidas e os resultados de resistência à tração. Para atingir os objetivos, uma máquina de soldagem por friç̧ão convencional foi desenvolvida. O preaquecimento do aço foi realizado por indução eletromagnética. As juntas soldadas foram submetidas a ensaio de tração e ensaios metalográficos utilizando o Microscópio Eletrônico de Varredura (MEV).
\end{abstract}

Palavras-chave: Soldagem à fricção; Parâmetros; Materiais dissimilares; Preaquecimento; Compostos intermetálicos.

\section{Growth of Intermetallic Compunds in Rotary Friction Welding of Aluminium and Steel, Assisted with Preheating by Eletromagnetic Induction}

\begin{abstract}
Welding of dissimilar aluminum and steel joints can be achieved by friction process, which is a solid state welding process. This process occurs at temperatures below the melting point of the metals, and have as main bonding mechanism, diffusion. It is an interesting bonding process option because it generates low residual stress, less distortion and low crack formation. However one of the major challenges of weld dissimilar materials is the no formation of intermetallic compounds, which can reduce the mechanical strength of the joints. This work presents the butt welding by rotary friction of Aluminum ASTM A6351 T6 and SAE 1020 Steel. It aims to evaluate the growth of intermetallic interlayers, without the use of steel preheating, and also with steel preheating. It also aims to evaluate structures obtained and the results of tensile strength. To achieve the objectives, a conventional friction welding machine was developed for research. The preheating of the steel was performed by electromagnetic induction. The welded joints were submitted to tensile and metallographic tests using SEM (Scanning Electron Microscope).
\end{abstract}

Key-words: Friction welding; Parameters; Dissimilar materials; Preheating; Intermetallic compounds.

\section{Introdução}

A necessidade de redução de peso, aliada à necessidade de estruturas com alto desempenho mecânico principalmente no setor aeroespacial e no setor automobilístico, bem como a necessidade de redução de consumo energético, resultaram no aumento de demanda por soldas de materiais dissimilares. Cada um destes materiais possui propriedades específicas que podem ser aproveitadas em diversas aplicações proporcionando soluções únicas combinadas [1-3]. Entretanto, realizar soldas desses materiais constitui um desafio tecnológico, tendo o processo de soldagem por fricção, uma alternativa interessante, haja

Recebido: 30 Maio, 2020. Aceito: 13 Nov., 2020.

E-mails: marlonpinheiro@cefetmg.br, queiroz@demec.ufmg.br

(i) Este é um artigo publicado em acesso aberto (Open Access) sob a licença Creative Commons Attribution Non-Commercial, que permite uso, distribuição e reprodução em qualquer meio, sem restrições desde que sem fins comerciais e que o trabalho original seja corretamente citado. 
vista que o processo ocorre no estado sólido, ou seja, abaixo dos pontos de fusão [4]. Especificamente estruturas híbridas de alumínio e aço têm chamado a atenção por combinar boas propriedades mecânicas do aço com baixa densidade e resistência à corrosão do alumínio.

A união desses materiais abaixo de seu ponto de fusão apresenta vantagens como diminuição de tensões residuais, distorções, não formação de trincas, estreita zona termicamente afetada, obtenção de juntas de alta qualidade e excelentes resultados mecânicos devido ao seu baixo aporte térmico, principalmente para materiais dissimilares $[3,5,6]$.

A soldagem por fricção de materiais dissimilares como aço e alumínio, por exemplo, tem sido muito estudada devido ao grande potencial de aplicação, vantagens e possibilidade de substituição de processos. Os princípios e parâmetros estão associados à geração de calor produzido pela conversão de energia mecânica em energia térmica, resultado do atrito entre duas partes que se movimentam relativamente, caldeamento dos materiais, aplicação de força para aproximar as superfícies a serem unidas, escoamento plástico dos materiais, consequentemente, arraste de óxidos superficiais, e formação da borda conhecida também como flash [6,7]. Entretanto, a severa deformação plástica, associada à temperatura, provoca o amolecimento do alumínio, leva à ruptura do filme de óxidos, que são expulsos do centro para a borda, formando novas superfícies, aumentando a difusão e a formação de compostos intermetálicos entre o alumínio e aço [3].

Dawood et al. [8] ressalta, em seus estudos, que uma das desvantagens do processo é a não uniformidade de espessura da zona termicamente afetada. O motivo é causado pelo aquecimento não uniforme na interface, resultado da alteração na velocidade de rotação, que ocorre do centro da peça em relação à sua extremidade. Isso afeta também a espessura das camadas dos compostos intermetálicos ao longo da junta soldada.

As variáveis do processo de soldagem por fricção, segundo Khan [4], relativas à máquina são a rotação ou velocidade de contato entre as duas superfícies, força de contato e também a força de forjamento, além dos tempos de aplicação das respectivas forças. As variáveis que não são associadas à máquina são os tipos de materiais que serão unidos, a geometria e o diâmetro das peças.

Ogawa et al. [9] afirma que, no caso específico da soldagem de alumínio e aço, a formação de compostos intermetálicos é comum e interfere negativamente, prejudicando a difusão entre alumínio e aço, interferindo nas propriedades mecânicas, haja vista que, no diagrama de equilíbrio Fe-Al, não há solubilidade entre os dois elementos.

Quando se trata de soldagem por fricção de materiais dissimilares, vários estudos apontam os desafios de realizar o processo. Segundo Ambroziak [10], na soldagem de ligas de alumínio com aço, ocorre a presença de formação de fases intermetálicas. O autor apresentou recomendações de parâmetros para soldagem, entretanto afirma que vários testes são necessários para obter os parâmetros ideais que conduzem a melhores resultados de resistência mecânica. Yilbas e Sahin [11] e Fukumoto et al. [12] realizaram soldas por friç̧ão das ligas de alumínio e cobre, alumínio e aço, afirmando que, ao soldar esses metais, surgem problemas não apenas relacionados às diferentes durezas e pontos de fusão, mas também da possibilidade de geração de fases intermetálicas frágeis ou elementos com baixo ponto de fusão. Especificamente na soldagem de alumínio e aço, os autores relataram que o maior problema foi a formação de compostos intermetálicos, bem como a distribuição dos mesmos.

Vários pesquisadores têm estudado as interações metalúrgicas existentes durante a formação da junta soldada de materiais dissimilares, haja vista que, durante o processo, os metais a serem soldados, são submetidos, ao mesmo tempo, ao aquecimento e deformação plástica [11]. Hu et al. [13] desenvolveu um método para soldagem por friç̧ão de alumínio e cobre,utilizando-se de um material intermediário, que realiza a fricção entre as duas superfícies, de forma independente, retirando o contato entre as duas superfícies soldadas durante a fricção, tendo como resultado a inexistência de camadas intermetálicas e excelente resistência à tração.

A soldagem por friç̧ão de materiais dissimilares assistida com preaquecimento foi estudada por Tavares [2] o qual concluiu que é possível obter resultados de resistência à tração, com tempo menor de atrito. Além do tempo menor, a indução permite, na soldagem por fricção, a utilização de máquinas de menor capacidade para a realização de soldas de materiais menos dúcteis, essa técnica também é chamada de LFFW (Low Force Friction Welding) por MTI [14] os quais afirmam que soldas por fricção, de alta qualidade, podem ser obtidas a partir de uma fonte externa de calor. Apresentam também que o preaquecimento possui outras vantagens além da redução do ciclo de soldagem, como menor custo e dimensões do equipamento a ser utilizado, menor força utilizada, maior precisão dimensional das peças soldadas, menor consumo de material e redução de tensões residuais.

Este trabalho tem como objetivo mostrar o crescimento da camada intermetálica formada durante a soldagem de juntas de topo, por fricção, do alumínio 6351 T6 e aço SAE 1020, com preaquecimento e sem preaquecimento do aço, por indução eletromagética, além disso pretende-se relacionar a formação de compostos, e outras possíveis alterações estruturais, com os resultados de resistência à tração.

\section{Materiais e Métodos}

\subsection{Equipamentos de soldagem utilizados}

Para a realização da pesquisa, foi utilizada uma máquina de soldagem por fricção rotativa convencional, mostrada na Figura 1, desenvolvida para realização de pesquisas. 


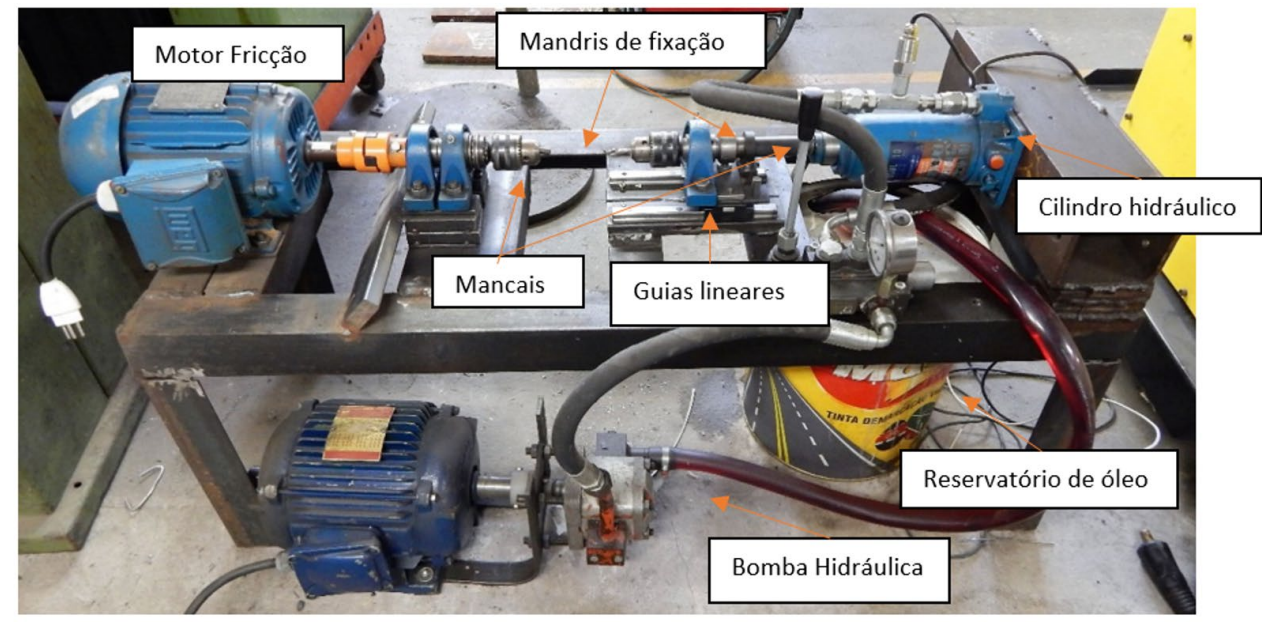

Figura 1. Máquina de soldagem por fricção vista superior.

O preaquecimento do aço foi feito adaptando-se um indutor eletromagnético, instalando sistema de acionamento e carcaça de proteção. A Figura 2 mostra o indutor marca ZVS utilizado para o preaquecimento, que possui como especificações técnicas, tensão de $12 \mathrm{~V}, 120$ watts de potência, frequência de indução de $217 \mathrm{kHz}$ comprimento da bobina de $28 \mathrm{~mm}$, diâmetro externo $21 \mathrm{~mm}$, e diâmetro interno de 17,9 mm. Foi colocada uma proteção e um acionamento para o indutor.
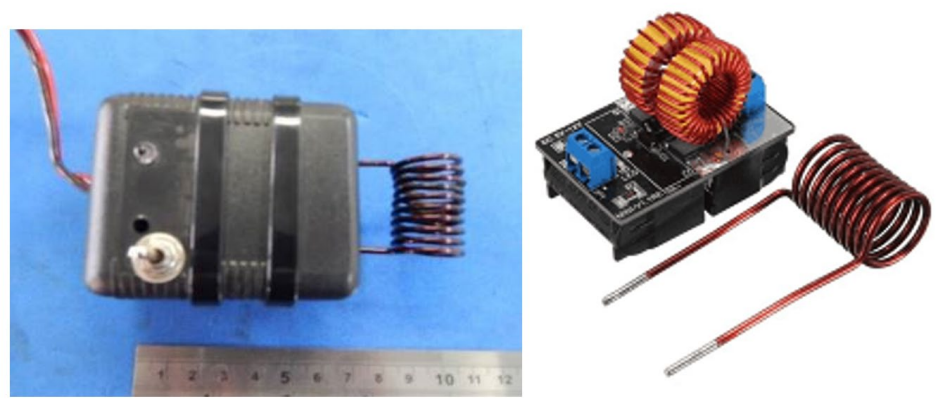

Figura 2. Indutor utilizado para preaquecimento.

O preaquecimento ocorre após a fixação das peças no mandril, seguido da limpeza das superfícies com Acetona PA e, posteriormente, o aquecimento por indução, conforme Figura 3, com sua respectiva imagem ampliada, as etapas do processo de soldagem por atrito das peças de alumínio e aço ocorrem na sequência.

O tempo utilizado de indução foi de 1 minuto, sendo possível atingir uma temperatura de $300^{\circ} \mathrm{C}$ na região central da face de contato do aço, que será submetida à friç̧ão rotativa com o alumínio. As medições foram feitas utilizando-se câmera termográfica.

É importante salientar que o processo de aquecimento por indução é caracterizado por uma distribuição não homogênea de corrente no interior do indutor e da peça. A densidade de corrente é maior na superfície do condutor e reduz em direção ao centro. Esse fenômeno é conhecido como efeito pelicular ou profundidade de penetração [2].

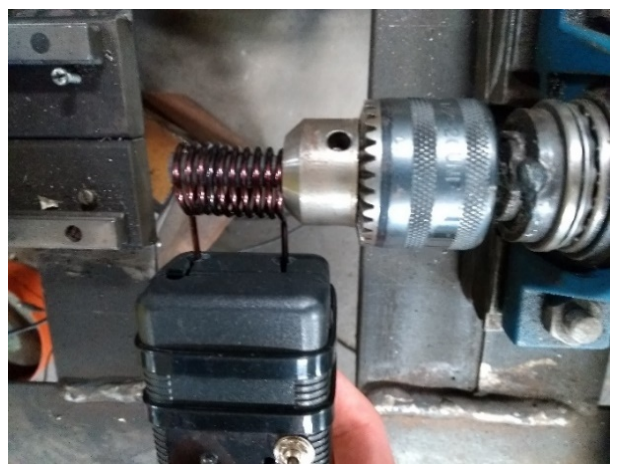

Figura 3. Procedimento de indução eletromagnética. 


\subsection{Materiais e preparação da superfície}

Foram utilizadas barras de alumínio 6351-T6 e aço SAE 1020 de diâmetro de 3/8"(9,53 mm), com comprimentos de 50mm para o aço e $55 \mathrm{~mm}$ para o alumínio. A escolha desses dois materiais se deve à grande utilização em diversas aplicações na indústria automotiva, aeronáutica e indústrias em geral. A composição química nominal dos materiais utilizados está apresentada na Tabela 1 e, na Tabela 2, as propriedades mecânicas.

Tabela 1. Composição química dos materiais utilizados.

\begin{tabular}{lccccccccccc}
\hline \multicolumn{1}{c}{ Material } & \multicolumn{1}{c}{ Elementos (\% peso) } \\
\cline { 2 - 8 } & $\mathrm{Si}$ & $\mathrm{Fe}$ & $\mathrm{Cu}$ & $\mathrm{Mn}$ & $\mathrm{Mg}$ & $\mathrm{Cr}$ & $\mathrm{Zn}$ & $\mathrm{Ti}$ \\
Alumínio 6351 T6 & 1,30 & 0,50 & 0,10 & 0,80 & 0,08 & - & - & 0,22 \\
Aço SAE 1020 & $\mathrm{C}$ & $\mathrm{Mn}$ & $\mathrm{Si}$ & $\mathrm{P}$ & $\mathrm{S}$ & $\mathrm{Mo}$ & $\mathrm{Al}$ & $\mathrm{Ni}$ \\
& 0,19 & 0,48 & 0,07 & 0,01 & 0,01 & 0,00 & 0,02 & 0,01 \\
\hline
\end{tabular}

Tabela 2. Propriedades Mecânicas do Alumínio 6351 T6 e Aço SAE 1020.

\begin{tabular}{ccccccc}
\hline Liga & Têmpera & $\begin{array}{c}\text { Limite de Resistência } \\
\text { Tração } \mathbf{M P a}\left(\mathbf{N} / \mathbf{m m}^{2}\right)\end{array}$ & $\begin{array}{c}\text { Limite de Escoamento MPa } \\
\left(\mathbf{N} / \mathbf{m m}^{2}\right) \text { Mín. }\end{array}$ & $\begin{array}{c}\text { Alongamento } \\
\text { Mínimo" (\%) }\end{array}$ & $\begin{array}{c}\text { Dureza Brinell } \\
(\mathbf{H B})\end{array}$ \\
Al 6351 & T6 & 290 & 255 & 8 & 95 \\
AÇO SAE 1020 & - & 420 & 350 & 15 & 121 \\
\hline
\end{tabular}

As faces de contato das peças a serem soldadas foram usinadas em torno convencional e foi realizada uma limpeza das faces utilizando-se Acetona PA para a retirada de contaminantes orgânicos como óleo e graxa.

\subsection{Parâmetros de soldagem}

Há uma variedade de parâmetros fornecidos pela literatura, entretanto foi necessária a realização de testes preliminares para avaliar a processabilidade dos materiais, com alteração de parâmetros, com objetivo de definir quais seriam utilizados.

Inicialmente, sem preaquecimento, utilizaram-se tempos de soldagem a partir de $15 \mathrm{~s}$ que foram reduzindos gradativamente. Utilizando-se tempo acima de $9 \mathrm{~s}$, obtiveram-se soldas que se rompiam manualmente. Assim como, em tempos de soldagem menores que $4 \mathrm{~s}$, as amostras também se rompiam manualmente. A pressão de soldagem utilizada foi de $21,37 \mathrm{MPa}$, a menor pressão possível da máquina. Os parâmetros fixos utilizados foram a rotação com 1750 RPM e o tempo de forjamento de $6 \mathrm{~s}$.

Quanto às temperaturas, ficou definido que a temperatura de preaquecimento do aço foi de $300^{\circ} \mathrm{C}$. A definição ocorreu após testes com temperaturas de $250^{\circ} \mathrm{C}, 300^{\circ} \mathrm{C}$ e $350^{\circ} \mathrm{C}$, para tempos de atrito de $4 \mathrm{~s} \mathrm{e} 7 \mathrm{~s}$ que constataram que com $7 \mathrm{~s}$ de tempo de atrito, e temperatura de $350^{\circ} \mathrm{C}$, as amostras romperam manualmente. Adotou-se, portanto, $300^{\circ} \mathrm{C}$ de preaquecimento, máxima temperatura em que as amostras soldadas não se romperam manualmente.

Portanto, os parâmetros foram definidos em: tempos de soldagem de 4 e 7 s e temperaturas de $25^{\circ} \mathrm{C}$ (ambiente) e $300^{\circ} \mathrm{C}$ (Preaquecimento). Foram utilizadas as pressões de soldagem, 21,37 MPa e 37,00 MPa, sendo que a pressão de forjamento utilizada foi a mesma da pressão de soldagem.

Foi feito um planejamento fatorial completo, de dois níveis, com 3 réplicas, resultando em $2^{3} \times 3$ (réplicas), resultando em 24 amostras soldadas para os ensaios de tração.

\subsection{Análises da Interface da junta soldada por MEV e EDS}

Após a soldagem, as juntas foram cortadas no sentido transversal da solda, embutidas, polidas e examinadas na região da interface, do lado do alumínio e do lado do aço, conforme a norma ASTM-E3 [15]. O alumínio foi atacado com reagente Keller e o aço, com reagente Nital 2\% e analisado em um Microscópio Eletrônico de Varredura (MEV).

Foi possível verificar a estrutura das juntas soldadas, realizar as medições das espessuras das camadas intermetálicas. Essas medições ocorreram na região central e três medições a cada $1 \mathrm{~mm}$ em relação ao centro, apresentadas na Figura 4, bem como a composição química através da Espectroscopia de Energia Dispersiva(EDS) e por EDX (Difração de Raio X), na interface da solda. 


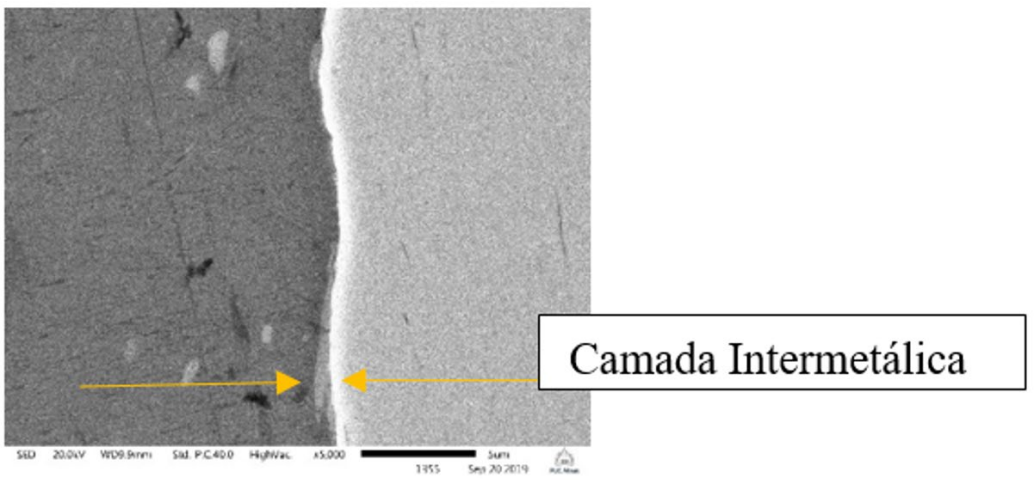

Figura 4. Exemplo de medição de camada intermetálica.

\subsection{Ensaio de tração}

Os ensaios de tração foram realizados em uma máquina de ensaio de tração da marca EMIC, modelo D20000, capacidade de $20 \mathrm{KN}$. O teste foi executado com velocidade de ensaio de $1 \mathrm{~mm} / \mathrm{min}$. Foram feitas três amostras para cada experimento realizado.

\subsection{Medição de temperatura}

As temperaturas obtidas foram feitas por câmera termográfica, da marca Flir, modelo SC 600 . A Figura 5 apresenta o posicionamento da câmera termográfica para a realização das medições.

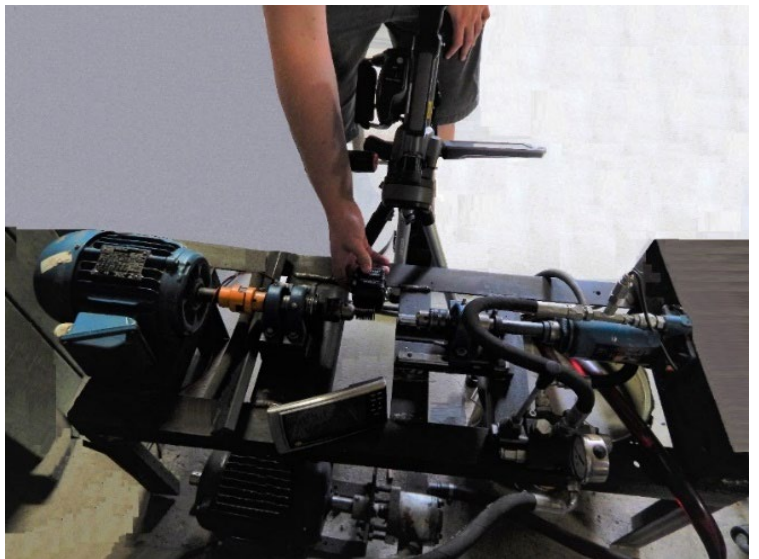

Figura 5. Medição da temperatura com Câmera Termográfica.

\section{Resultados e Discussão}

A Figura 6 apresenta duas peças soldadas por friç̧ão, sendo que em uma peça não foi utilizado preaquecimento e, na outra, utilizou-se o preaquecimento a $300^{\circ} \mathrm{C}$ antes da soldagem por atrito. Verifica-se que, nas amostras onde o aço foi preaquecido, apresenta-se aumento da borda.
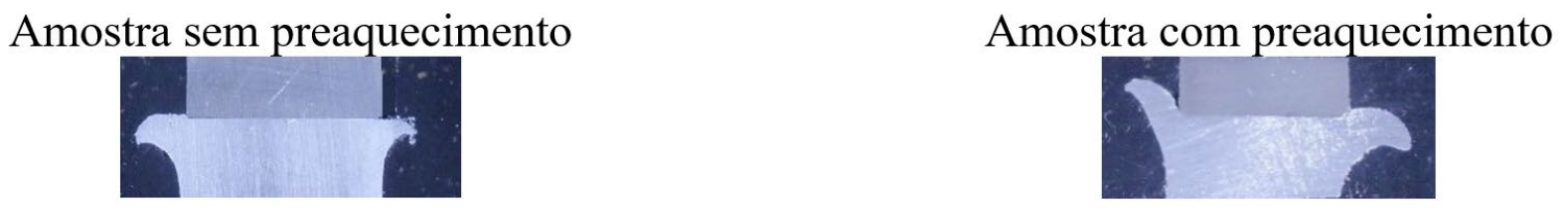

Figura 6. Amostras soldadas por fricção Sem Preaquecimento e Com preaquecimento do aço a $300^{\circ} \mathrm{C}$.

Na soldagem do aço e do alumínio, por fricção, ocorrem deformações diferentes entre aço e alumínio em relação ao plano de interface da junta soldada. Essas diferenças também são chamadas de deformações assimétricas, causadas pelas diferenças de propriedades térmicas, físicas e químicas, como ponto de fusão, dureza, condutividade térmica dos dois materiais [16]. 0 alumínio possui alta condutividade térmica, menor dureza e ponto de fusão mais baixo, portanto deforma mais que o aço. $\mathrm{A}$ 
pouca deformação do aço pode levar à remoção incompleta de filmes de óxidos e outros elementos. Observou-se que mesmo preaquecido a $300^{\circ} \mathrm{C}$, as diferenças de deformação entre o aço e o alumínio permaneceram. Vale salientar que essas diferenças nas deformações dos materiais foram relatadas também em outras soldagens de materiais dissimilares, alumínio-cobre, titânio e aço, entre outros $[6,12,17]$.

Outra constatação é que apenas o alumínio participou da formação da borda, substanciada pelo encurtamento apenas da haste de alumínio.

\subsection{Perfil térmico do processo}

As Figuras 7A e 7B apresentam a distribuição de calor, obtidas com câmera termográfica, nas juntas soldadas.
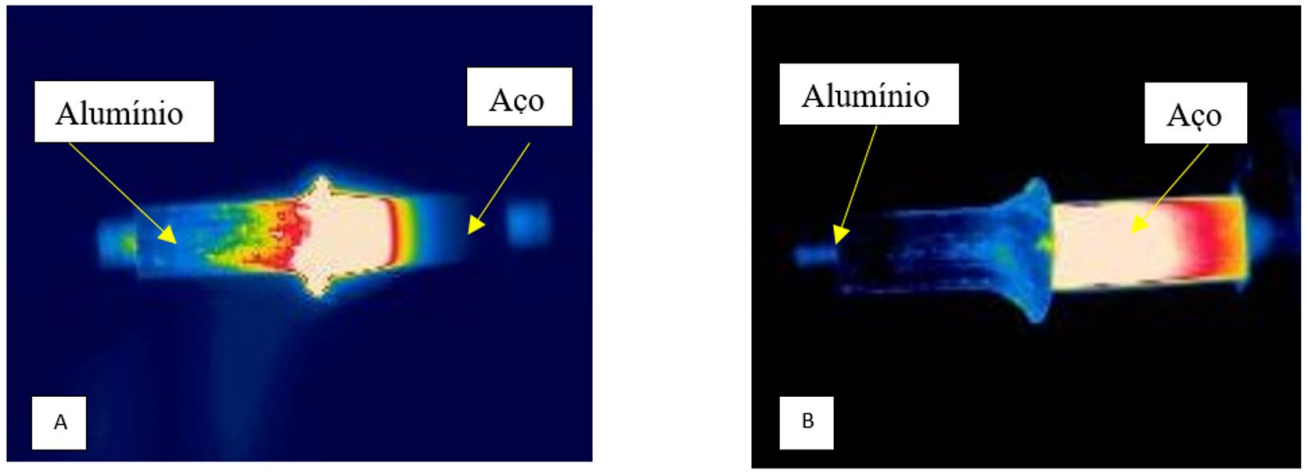

Figura 7. Distribuição das temperaturas (a) Sem Preaquecimento; (b) Com Preaquecimento.

Verifica-se, nas Figuras 7A e 7B, que o calor se difunde diferentemente em cada material. O alumínio possui uma condutividade térmica quase três vezes maior do que o aço, o que influencia diretamente o aquecimento e resfriamento no processo, permitindo que o alumínio dissipe o calor mais rapidamente. Segundo Zyakhor [18], essa assimetria da temperatura com a deformação plástica é a principal característica da soldagem de materiais dissimilares.

A Figura 8 apresenta as curvas de temperatura obtidas durante o processo de soldagem por atrito. As amostras sem preaquecimento começam a aumentar a temperatura a partir de $1 \mathrm{~s}$, atingem a temperatura máxima de $342,4^{\circ} \mathrm{C}$, para tempo de atrito de $4 \mathrm{~s}$. Para o tempo de atrito de $7 \mathrm{~s}$, a máxima temperatura obtida foi de $378,4^{\circ} \mathrm{C}$.

As amostras com preaquecimento, começam o atrito com temperaturas mais elevadas; acima de $400^{\circ} \mathrm{C}$ e atingem $\mathrm{O}$ máximo de temperatura de $460,4^{\circ}$ para ambas as amostras. A amostras preaquecidas permanecem com temperatura próxima ou acima de $400^{\circ} \mathrm{C}$ durante todo o tempo de atrito.

As consequências disso são o aumento da zona termicamente afetada, alterações de tamanhos de grãos e possíveis formações ou aumento de compostos intermetálicos [19]. Outra consequência são o aumento da formação das bordas e encurtamento maior das hastes de alumínio.

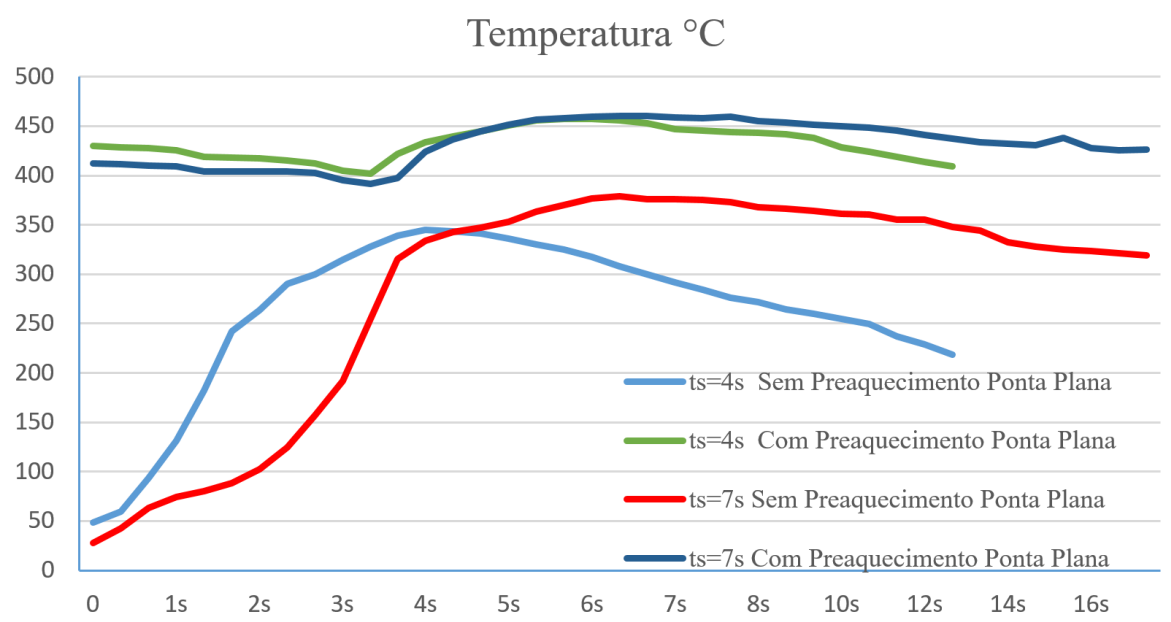

Figura 8. Perfil térmico Soldagem sem preaquecimento e com preaquecimento. 


\subsection{Resultados ensaios de tração}

Os corpos de prova foram submetidos a Ensaios de Tração, com objetivo de se verificar a eficiência das juntas soldadas, foram realizados os ensaios de tração, sendo que os corpos de prova foram usinados para esse fim, conforme norma ASTM E8M [20] (Figura 9).

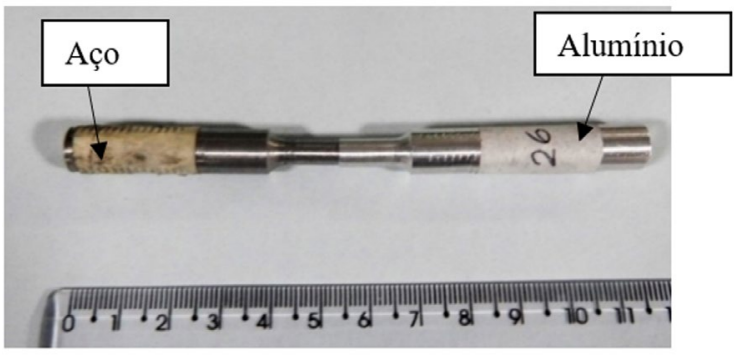

Figura 9. Corpo de prova usinado para ensaio de Tração.

A Figura 10 apresenta os resultados dos Limites de Resistência à Tração, bem como os respectivos parâmetros utilizados. É importante destacar que as rupturas dos corpos de prova ocorreram nas juntas soldadas.

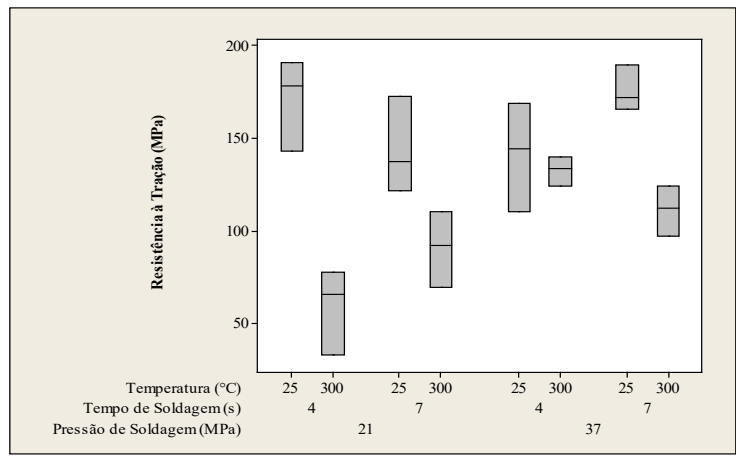

Figura 10. Resultados de Resistência à Tração.

Verifica-se que não utilizar o preaquecimento favoreceu a obtenção de resultados de Resistência à tração maiores.

A dispersão dos resultados, observadas na Figura 10, para os valores tensão de ruptura das amostras que não foram preaquecidas, indica a heterogeneidade dos corpos de prova ensaiados. Essa heterogeneidade do processo realizado à temperatura ambiente pode ser causada pela maior dificuldade em aquecer, somente por atrito e iniciar a deformação dos materiais a serem unidos. Observa-se também maior vibração durante o processo sem preaquecimento.

A Figura 11 apresenta a Análise do Efeitos dos parâmetros utilizados nos resultados de Resistência à Tração, através da Regressão Linear. Verifica-se que não houve interação entre os parâmetros na obtenção dos resultados de ensaio de tração.

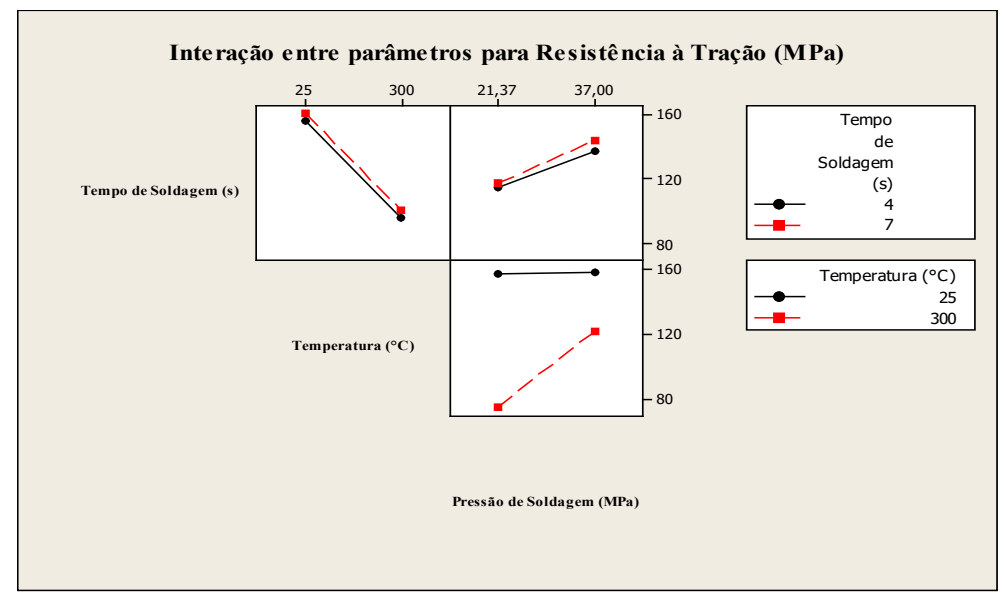

Figura 11. Análise da interação entre os parâmetros nos resultados de Resistência à Tração. 
A Análise de Regressão também foi utilizada para avaliar qual fator influenciou mais nos resultados de Resistência à Tração. A Figura 12 apresenta os resultados e mostra que o parâmetro que mais influenciou os resultados de Resistência à tração foi a temperatura de preaquecimento. O segundo parâmetro que mais influenciou foi a pressão de soldagem que, de um modo geral, contribuiu para o aumento da resistência à tração.

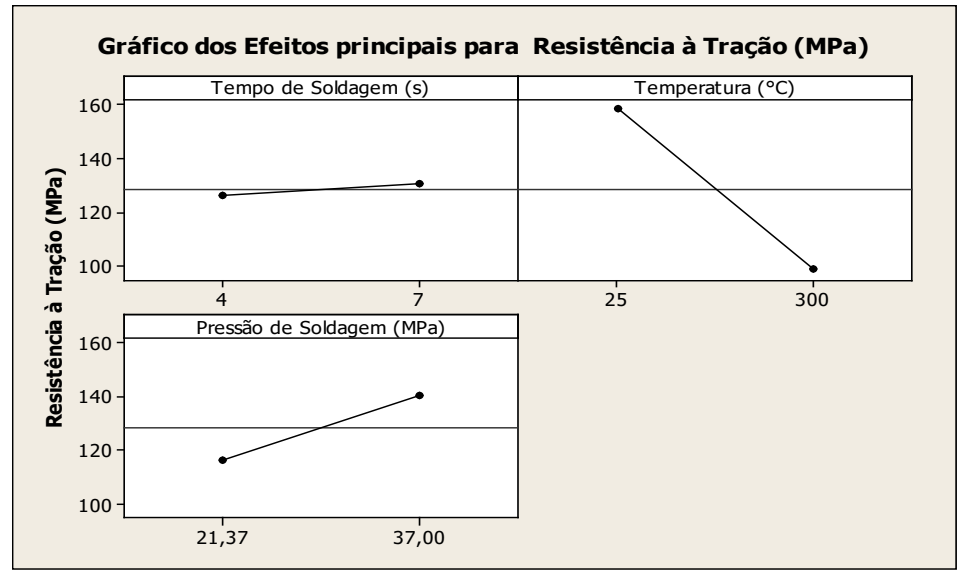

Figura 12. Gráfico dos efeitos dos parâmetros nos resultados de Resistência à Tração.

\subsection{Resultados das análises metalográficas}

As Figuras 9 e 10 apresentam as estruturas da região central das amostras soldadas sem preaquecimento e com preaquecimento Observa-se que tanto nas amostras das juntas soldadas da região central, sem preaquecimento e com preaquecimento, a interface é caracterizada por deformação típica da soldagem por fricção rotativa.

Verifica-se também deformação granular do aço na amostra preaquecida na junção da solda. Outra constatação é a ocorrência de descontinuidades nas amostras. Maiores descontinuidades foram observadas nas amostras preaquecidas, que estão distribuídas em toda amostra. Essas descontinuidades têm como explicação alguns fatores importantes, como, as diferenças de propriedades térmicas entre os materiais, especialmente o coeficiente de dilatação e o próprio aumento da espessura da camada intermetálica nas peças preaquecidas, que afetam a consolidação da interface da solda, afetando as propriedades mecânicas [7].

A interface da solda consiste em grãos finos, enquanto a periférica grãos grosseiros. O tamanho dos grãos da região central se deve ao processo de recristalização dinâmica. Esta diminuição dos grãos no lado do aço é consequência, conforme afirma Yamamoto et al. [19], aos efeitos da temperatura e aplicação de força. Acrescentado ao calor e força, a rotação provoca cisalhamento dos planos cristalinos, provocando além da diminuição do tamanho dos grãos e alongamento dos mesmos.

As Figuras 13 e 14 também apresentam as regiões formadas pelo processo, a região 4 se refere ao material base; a região 3 apresenta a região de recristalização parcial do material; a região 2 apresenta a zona termomecanicamente afetada onde os grãos se apresentam significativamente menores. Essa recristalização se deve aos efeitos da temperatura e aplicação de força. A região 1 apresenta a zona de interface, ou seja, a região de formação de possíveis compostos intermetálicos [21].
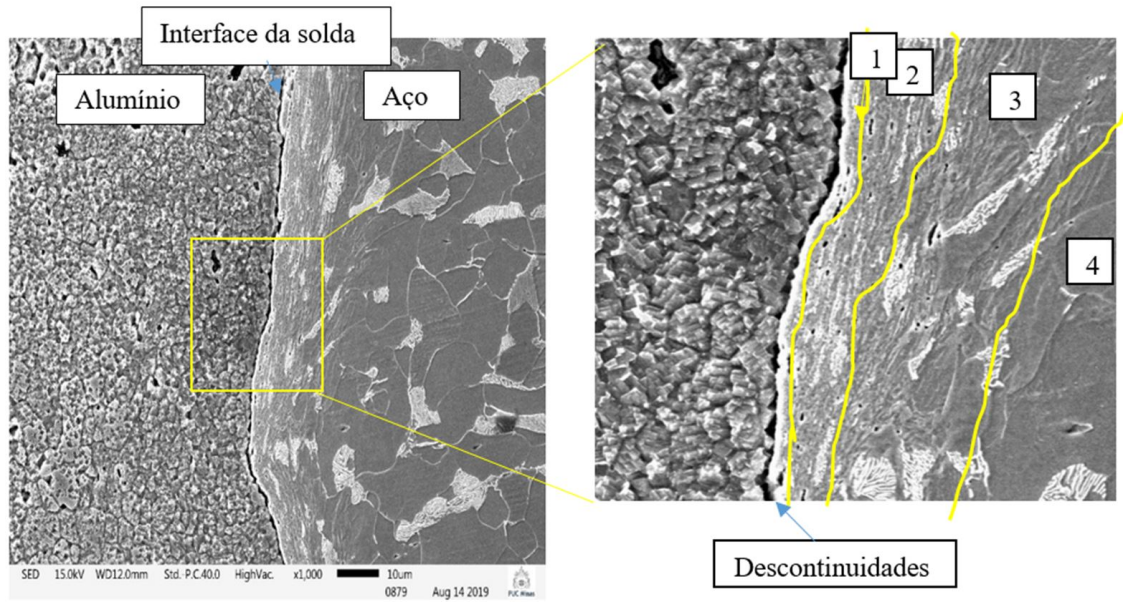

Figura 13. MEV da Região central da amostra sem preaquecimento. 

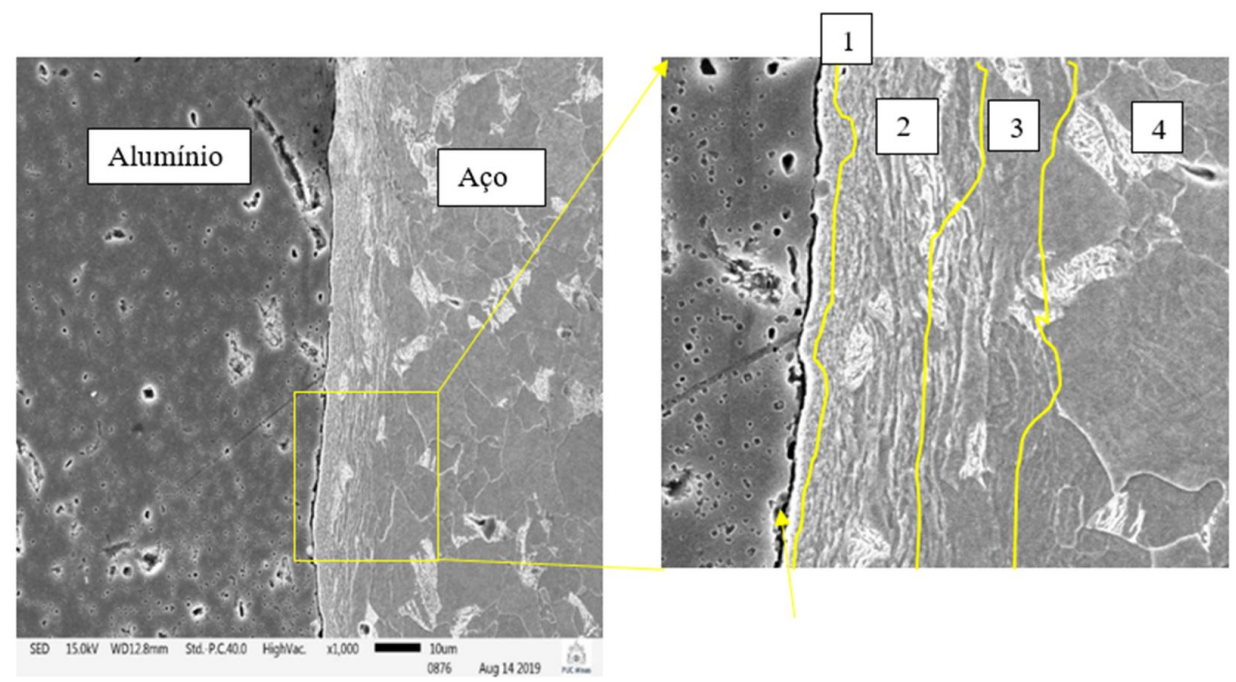

Figura 14. MEV da Região central da amostra com preaquecimento.

As Figuras 15 e 16 apresentam a relação entre a espessura das camadas intermetálicas e os resultados de Resistência à Tração, respectivamente, para tempo de soldagem de $4 \mathrm{~s}$ e $7 \mathrm{~s}$. Os resultados apontam a tendência de que, com aumento das camadas intermetálicas, ocorre diminuição da resistência à tração.

Nas amostras preaquecidas, ocorre aumento das espessuras das camadas intermetálicas devido ao maior aporte térmico durante o processo, favorecendo a difusão e crescimento da camada. É importante citar que o crescimento da camada acontece pelo fenômeno da difusão, e também pelo estado de deformação.

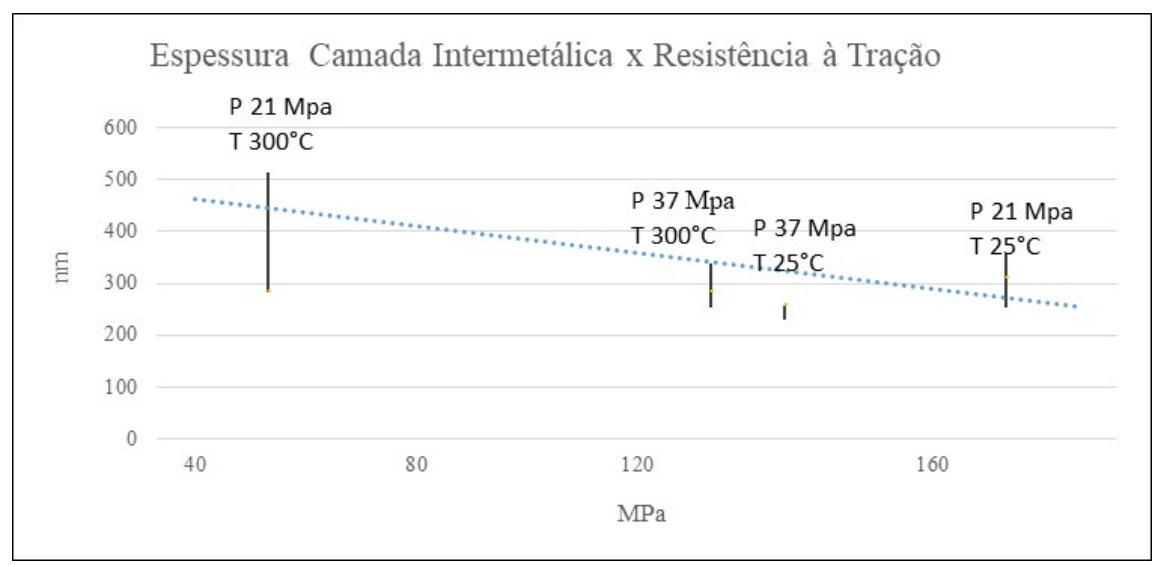

Figura 15. Relação entre Resistência à Tração e Espessura Camada Intermetálica Tempo de Soldagem de 4s.

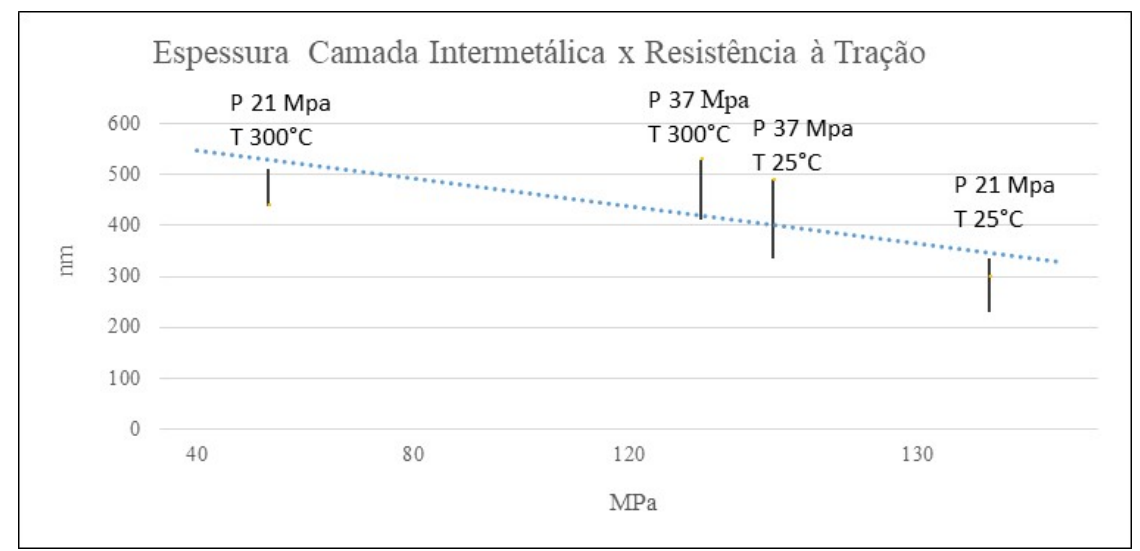

Figura 16. Relação entre Resistência à Tração e Espessura Camada Intermetálica Tempo de Soldagem de 7s. 
A espessura da camada intermetálica obtida é extremamente importante, mas também o tipo de composto formado desempenha um papel significativo na obtenção de juntas.

A análise por EDS (Espectroscopia de Energia Dispersiva), análise semiquantitativa, foi realizada nos pontos apresentados nas Figuras 17A e 17B. A Tabela 3 apresenta os resultados de composição química da camada intermetálica.
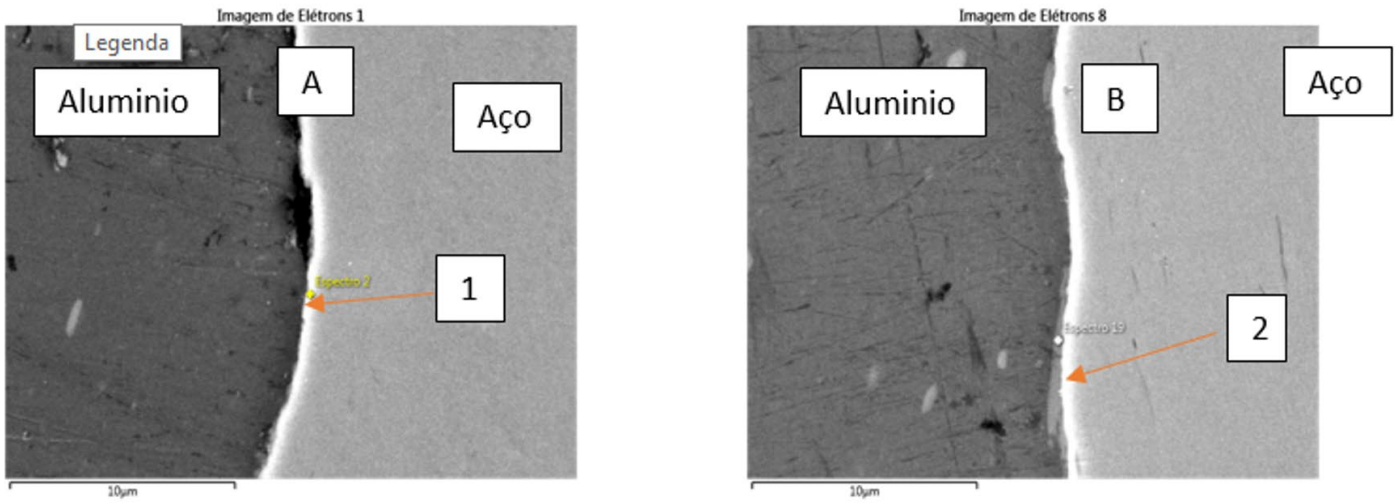

Figura 17. Ponto de análise por EDS Região central da amostra (A) Sem Preaquecimento; (B) Com Preaquecimento.

Tabela 3. Composição química \% Peso Elemento EDS.

\begin{tabular}{cccccccc}
\hline Pontos & Al & Fe & Mg & si & Mn & 0 \\
Ponto 1 & 28,92 & 68.09 & 0,08 & 0,32 & 1,63 & - \\
Ponto 2 & 25,8 & 71,1 & - & 1,3 & 1,2 & 0,7 \\
\hline
\end{tabular}

Pelas análises por EDS, no ponto 1 e ao longo da amostra sem preaquecimento, é possível verificar que o principal composto identificado seja o FeAl nas duas amostras. Entretanto, utilizando-se a Técnica de Difração de Raio X, feita após a ruptura dos corpos de prova no ensaio de tração, apresentada nas Figuras $18 \mathrm{~A}$ e $18 \mathrm{~B}$, não ocorreu a formação de compostos intermetálicos na camada interfacial, resultando somente na interdifusão do alumínio e Ferro.

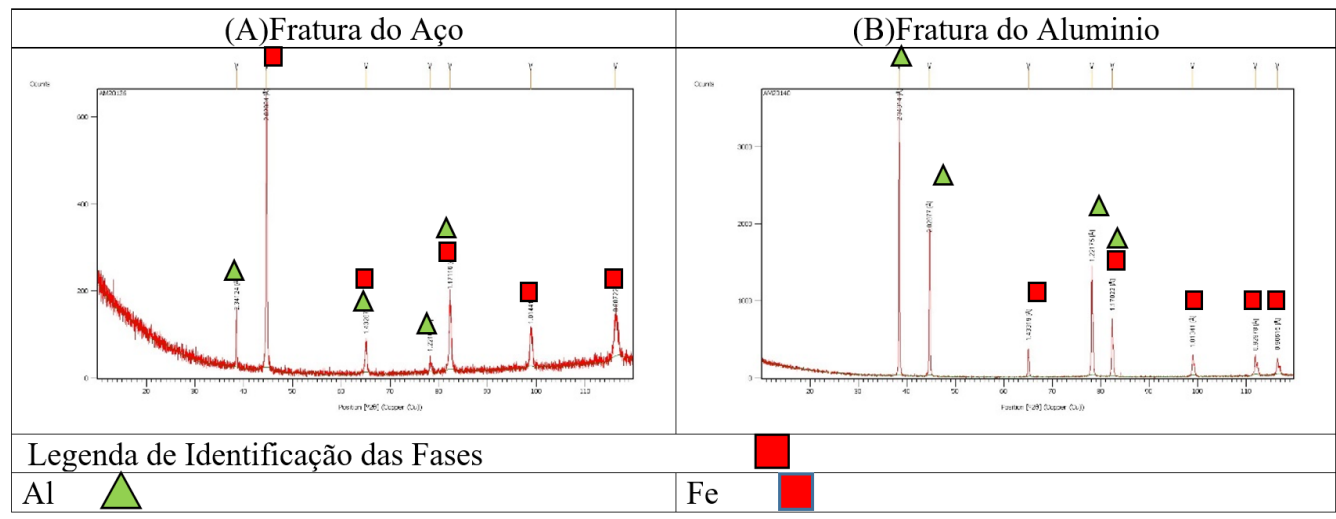

Figura 18. Análise por Difração de Raio X.

\section{Conclusões}

1. Nos testes realizados, com soldagem por fricção rotativa, os resultados de resistência à tração foram inferiores com preaquecimento, entretanto o preaquecimento, de modo geral, permite maior homogeneidade dos resultados de Resistência à Tração;

2. Existe uma relação entre o aumento da espessura das camadas intermetálicas, com a diminuição da resistência à tração. O crescimento das camadas intermetálicas é favorecido pelo maior aporte térmico que ocorre no preaquecimento;

3. Na análise estrutural, nas amostras preaquecidas, além de aumento da estrutura granular, ocorreram descontinuidades ao longo de toda amostra, ao passo que, nas amostras sem preaquecimento, as descontinuidades ocorreram em pontos específicos. Essas descontinuidades também influenciam os resultados de Resistência à tração; 
4. Na camada intermetálica, não houve formação de compostos intermetálicos. A formação desses compostos depende de aporte térmico, mas também de um tempo maior para a formação de tais compostos.

\section{Agradecimentos}

Os autores gostariam de agradecer aos membros do Laboratório de Robótica, Soldagem e Simulação da Universidade Federal de Minas Gerais (UFMG), ao Centro Federal de Educação Tecnológica de Minas Gerais (CEFET-MG) e à Pontifícia Universidade Católica de Minas Gerais (PUC-MG).

\section{Referências}

[1] Palanivel R, Dinaharan I, Laubscher RF. Assessment of microstructure and tensile behavior of continuous drive friction welded titanium tubes. Materials Science and Engineering A. 2017;687:249-258. http://dx.doi.org/10.1016/j.msea.2017.01.090.

[2] Tavares SS. Soldagem por fricção convencional entre a liga de alumínio 6351-T6 e o Aço SAE 1020 assistida por indução eletromagnética [dissertação de mestrado]. Belo Horizonte: Universidade Federal de Minas Gerais; 2017.

[3] Bozzi S, Helbert-Etter AL, Baudin T, Criqui B, Kerbiguet JG. Intermetallic compounds in Al 6016/IF-steel friction stir spot welds. Materials Science and Engineering A. 2010;527(16-17):4505-4509. http://dx.doi.org/10.1016/j.msea.2010.03.097.

[4] Khan IA. Experimental and numerical investigation on the friction welding process [doctor thesis]. India: Jawaharlal Nehru Technological University; 2011.

[5] Gipiela ML. Influência dos parâmetros de processo na geração de defeitos na soldagem FSW da liga de alumínio 5052 [dissertação de mestrado]. Curitiba: Universidade Federal do Paraná; 2007.

[6] Machado I. Soldagem e técnicas conexas, processos. Porto Alegre: Ed. Pelo Autor; 1996.

[7] Wainer E, Brandi SD, Melo VDO. Soldagem: processos e metalurgia. 1. ed. São Paulo: Edgard Blucher; 1992. 504 p.

[8] Dawood A, Butt S, Hussain G, Siddiqui M, Maqsood A, Zhang F. Thermal model of rotary friction welding for similar and dissimilar metals. Metals. 2017;7(6):224. http://dx.doi.org/10.3390/met7060224.

[9] Ogawa K, Ochi H, Yamamoto Y, Suga Y. Friction welding of aluminum alloy and steel. International Journal of Offshore and Polar Engineering. 1998;8(2):140-143.

[10] Ambroziak A. Badania zgrzewanych tarciowo złączy AlMg3 stal austenityczna. [S.I.]: Inzynieria Materialowa; 2003.

[11] Yilbas BS, Sahin AZ. Friction welding: thermal and metallurgical characteristics. Berlin: Springer-Verlag Heidelberg; 2014.71 p. http://dx.doi.org/10.1007/978-3-642-54607-5.

[12] Fukumoto S, Tsubakino H, Okita K, Aritoshi M, Tomita T. Static joint strength of friction welded joint between aluminium alloys and stainless steel. Welding International. 2000;14(2):89-93. http://dx.doi.org/10.1080/09507110009549145.

[13] Hu Y, Tsujino R, Higashi T, Ueda Y, Iguchi M. Development of Al/Cu dissimilar joint by new friction welding method. Journal of Japan Society for Design Engineering. 2016;51(3):181-196.

[14] MTI Welding-Friction Welding. Low force friction welding. [acesso em 2 jul. 2019]. Disponível em: https://www.mtiwelding.com/lowforce-friction-welding/

[15] American Society for Testing and Materials. ASTM-E3. West Conshohocken: ASTM; 2017.

[16] Mehta KP. A review on friction-based joining of dissimilar aluminum-steel joints. Journal of Materials Research. 2019;34(1):78-96. http://dx.doi.org/10.1557/jmr.2018.332.

[17] Sammaiah P, Suresh A, Tagore GRN. Mechanical properties of friction welded 6063 aluminum alloy and austenitic stainless steel. Journal of Materials Science. 2010;45(20):5512-5521. http://dx.doi.org/10.1007/s10853-010-4609-y.

[18] Zyakhor IV. Peculiarities of friction welding of dissimilar metals and alloys. Paton Welding Journal C/C of Avtomaticheskaia Svarka. 2000;2000(5):36-44.

[19] Yamamoto N, Takahashi M, Aritoshi M, Ikeuchi K. Effect of interfacial layer on bond strength of friction-welded interface of Al-Mg5083 alloy to mild steel. Quarterly Journal of The Japan Welding Society. 2005;23(3):496-503. http://dx.doi.org/10.2207/qjjws.23.496.

[20] American Society for Testing and Materials. ASTM E8M. West Conshohocken: ASTM; 2016.

[21] Herbst S, Aengeneyndt H, Maier HJ, Nürnberger F. Microstructure and mechanical properties of friction welded steel-aluminum hybrid components after T6 heat treatment. Materials Science and Engineering A. 2017;696:33-41. http://dx.doi.org/10.1016/j.msea.2017.04.052. 